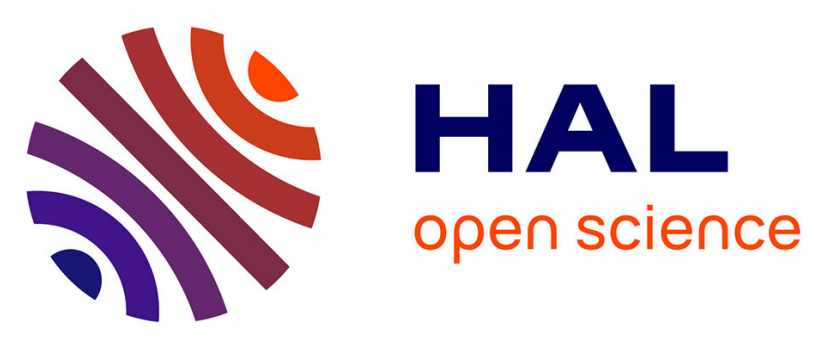

\title{
Identification of Burgers vectors along in In-doped GaAs, by X-ray transmission topography and image simulation.
}

\author{
N. Burle-Durbec, B. Pichaud, F. Minari, Alain Soyer, Yves Epelboin
}

\section{- To cite this version:}

N. Burle-Durbec, B. Pichaud, F. Minari, Alain Soyer, Yves Epelboin. Identification of Burgers vectors along in In-doped GaAs, by X-ray transmission topography and image simulation.. Journal of Applied Crystallography, 1986, 19 (2), pp.140-141. 10.1107/S0021889886089781 . hal-01214530

\author{
HAL Id: hal-01214530 \\ https://hal.science/hal-01214530
}

Submitted on 10 Nov 2015

HAL is a multi-disciplinary open access archive for the deposit and dissemination of scientific research documents, whether they are published or not. The documents may come from teaching and research institutions in France or abroad, or from public or private research centers.
L'archive ouverte pluridisciplinaire HAL, est destinée au dépôt et à la diffusion de documents scientifiques de niveau recherche, publiés ou non, émanant des établissements d'enseignement et de recherche français ou étrangers, des laboratoires publics ou privés. 


\section{Short Communications}

Contributions intended for publication under this heading should be expressly so marked; they should not exceed about 1000 words; they should be forwarded in the usual way to the appropriate Co-editor; they will be published as speedily as possible.

J. Appl. Cryst. (1986). 19, 140-141

\section{Identification of Burgers vectors along $\langle 111\rangle$ in In-doped GaAs, by X-ray transmission topography and image simulation. By N. Burle-Durbec, B. Pichaud and F. Minari, Laboratoire de Physique Cristalline, Unité Associée au CNRS, Université Aix-Marseille III, rue H. Poincaré, 13397 Marseille CEDEX 13, France and A. SOYER and Y. Epelboin, Laboratoire de Minéralogie et Cristallographie, Unité Associée au CNRS, Université Pierre et Marie Curie, \\ 4 Place Jussieu, 75230 Paris CEDEX 05, France}

(Received 15 July 1985; accepted 23 October 1985)

\begin{abstract}
Long dislocations with Burgers vectors along $\langle 111\rangle$ are unusual in f.c.c. lattices. X-ray topographs have been obtained of as-grown GaAs crystals doped with $10^{20}$ atoms $\mathrm{cm}^{-3}$ of In, where the usual extinction criterion $\mathbf{g} \cdot \mathbf{b}=0$ leads to this type of defect. However, for several $\mathbf{g}$ satisfying the condition $\mathbf{g} \cdot \mathbf{b}=0$ with $\mathbf{b}=a$ [111], the images of these dislocations were still clearly visible. Comparison between experimental and computer-simulated X-ray topographic sections of these defects confirms the existence of Burgers vectors along $\langle 111\rangle$.
\end{abstract}

Samples $15 \times 10 \times 0.3 \mathrm{~mm}$ have been sliced along $(110)$ from GaAs ingots grown by M. Duseaux at the LEP* by the liquid encapsulation Czochralski technique. The growing axis was [001]. The introduction during the growth of a relatively high concentration of In $\left(\sim 10^{20}\right.$ atoms $\left.\mathrm{cm}^{-3}\right)$ allows the quality of the material to be considerably improved up to dislocation densities of about $10^{3} \mathrm{~cm}^{-2}$ (Duseaux, Schiller, Cornier, Chevalier \& Hallais, 1983). These dislocations have been studied in the Laboratoire de Physique Cristalline by X-ray transmission topography using $\mathrm{Ag} \mathrm{K \alpha}$ radiation from a rotating anode (Pichaud, Burle-Durbec, Minari \& Duseaux, 1985). For most of them, the conventional $\mathbf{g} . \mathbf{b}=\mathbf{0}$ criterion leads unambiguously to the usual $a / 2\langle 110\rangle$ Burgers vectors, but for others the characterization is more difficult. Fig. 1 is a $2 \overline{2} 0$ translation topograph of such a group of dislocations. Among the 22 different reflections which have been used in this study, invisibility was obtained for $20 \overline{2}$ and $22 \overline{4}$, which leads to an unusual Burgers vector along [111]. But other reflections, while satisfying $\mathbf{g} . \mathbf{b}=0$ for $\mathbf{b}=a[111]$, gave a noticeable contrast. Since the simple criterion $\mathbf{g . b}=0$ is only valid for pure screw dislocations, we have used the general criterion $\mathbf{g} . \mathbf{R}=0(\mathbf{R}$ is the displacement vector around the dislocation line):

$$
\text { g. } \mathbf{R}(M)=\alpha \mathbf{g} . \mathbf{b}+\beta \mathbf{g} .[\mathbf{t} \times(\mathbf{b} \times \mathbf{t})]+\gamma \mathbf{g} .(\mathbf{b} \times \mathbf{t})
$$

(Tanner, 1976), $t$ is the unit vector along the dislocation line and $\alpha, \beta, \gamma$ depend on the coordinates of $M$.

\footnotetext{
*Laboratoire d'Electronique et de Physique Appliquée, 3 avenue Descartes, 94450 Limeil-Brévannes, France.
}

The determination of $\mathbf{g} . \mathbf{R}$ is unavoidably inaccurate owing to the difficulty of knowing exactly the orientation of the line. So, for a given $\mathbf{g}$, we made a series of calculations with different vectors $\mathbf{t}$ up to $5^{\circ}$ away from a mean direction taken as $(-0.19,-0.33,0.92)$. As an example, Table 1 gives the maximum value of $\mathbf{g . R}$ around the dislocation line for this mean direction and for six reflections. We noted that the relative variations of $\mathbf{g} . \mathbf{R}$ in this range of vectors $\mathbf{t}$ did not exceed $10 \%$, so the classification between the six values of Table 1 was not altered.

From these results, it can be seen that the dislocations can never be strictly invisible, but principally from comparison between the topographs and the corresponding values of g. $\mathbf{R}_{\max }$ it has been verified that the higher $\mathbf{g} . \mathbf{R}$ the stronger the experimental contrast, except for $20 \overline{2}$ and $02 \overline{2}$ for which the opposite situation occurs. So, a doubt subsisted about the identification of $\mathbf{b}=a$ [111] and it was necessary to confirm this unusual Burgers vector by some other method. The confirmation was achieved by computer simulation of section topographs of these dislocations. The calculation was made in the Laboratoire de MinéralogieCristallographie following a method previously published (Authier, Malgrange \& Tournarie, 1968; Epelboin, 1974). Section topographs are much more quickly computed than translation ones, and they contain more information, allow-

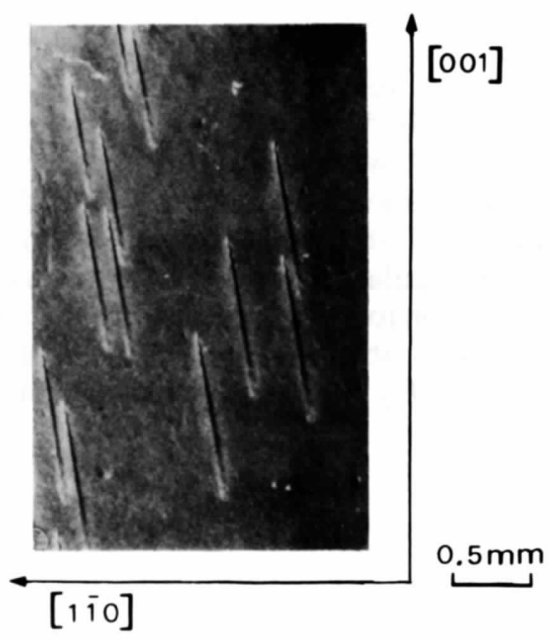

Fig. 1. Translation topograph, $\mathbf{g}=2 \overline{2} 0$. 
Table 1. Maximum values of $\mathbf{g} . \mathbf{R}$ around the dislocation line for six reflections

$\begin{array}{cc}\text { g } & (\text { g.R })_{\max } \\ 22 \overline{4} & 0 \cdot 40 \\ 20 \overline{2} & 1 \cdot 13 \\ 02 \overline{2} & 0 \cdot 79 \\ \overline{2} 20 & 1 \cdot 90 \\ \overline{2} 4 \overline{2} & 2 \cdot 68 \\ 4 \overline{2} \overline{2} & 3.02\end{array}$

ing more conclusive comparisons to be made with the experimental images. In this technique, the best images are obtained with the narrowest X-ray entrance slit. Fig. 2 is an experimental section of a dislocation of Fig. 1. The reflection was $\overline{4} 40$ and the entrance slit was $0.030 \mathrm{~mm}$ wide. This width is rather too large to provide a high-quality image, but it was imposed by our experimental set up. This situation and perhaps the relatively high In concentration can explain the absence of Pendellösung fringes in the experimental image. Fig. $3(a)$ is the corresponding computed image with a $0.001 \mathrm{~mm}$ wide 'theoretical' entrance slit, and the Burgers vector $a / 3$ [111]. The comparison is satisfactory and all other tentative Burgers vectors gave less resemblance. For instance, Fig. $3(b)$ is the same computed section with the Burgers vector $a / 2$ [110]. It can be seen that the distribution and the shape of the fringes do not fit the experimental topograph: the fringes are too abruptly curved and the bottom of the image is white instead of black. In Fig. $3(c)$ the theoretical slit width was increased to $0.017 \mathrm{~mm}$ (maximum value allowed by the program) and both parallel and perpendicular polarizations of the X-ray beam were introduced in the computation, to get more realistic conditions. The Burgers vector was again $a / 3$ [111]. Here the correspondence between experimental and theoretical images is quite good.

These results confirm the existence of Burgers vectors along $\langle 111\rangle$ in GaAs. Such a direction of Burgers vector is usually invoked for partial dislocations in f.c.c. structures, but these dislocations are associated with a stacking fault. In

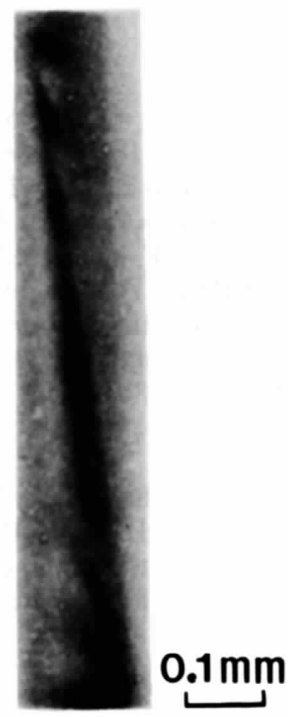

Fig. 2. Section topograph, $\mathbf{g}=\overline{4} 40$. our case, the resolution of the topographs and of the related simulation does not allow one to decide whether the defect is a perfect $a[111]$ dislocation (high-energy defect) or a complex defect involving two or more Frank partials associated with stacking faults. It must be recalled here that the defects involved in this study are growth defects and not purely stress-induced ones. In addition, the high concentration of In may induce the formation of particular defects, as happens in Te-doped GaAs where condensation of Te along \{111\} planes induces complex stacking faults (Maksimov, Ziegler, Khodos, Snighiryova \& Shikhsaidov, 1984). Finally, it must be pointed out that Burgers vectors along $\langle 111\rangle$ have already been observed within grain boundaries in Czochralski-grown Si (Bourret, Desseaux-Thibault \& Lancon, 1983).

This study demonstrates the usefulness of computational imaging techniques when the usual criteria of identification of defects do not lead to straightforward conclusions, and it shows again the influence of dopants on defect structure in semiconductors, particularly in III-V compounds.

\section{References}

Authier, A., Malgrange, C. \& Tournarie, M. (1968). Acta Cryst. A24, 126-136.

Bourret, A., Desseaux-Thibault, J. \& Lancon, F. (1983). J. Phys. Colloq. 4, 9, 44, 15-24.

Duseaux, M., Schiller, C., Cornier, J. P., Chevalier, J. P. \& Hallais, J. (1983). J. Phys. Colloq. 4, 9, 44, 397-407.

Epelboin, Y. (1974). J. Appl. Cryst. 7, 372-377.

Maksimov, S. K., Ziegler, M., Khodos, I. I., SNighiRyova, I. I. \& Shikhsaidov, M. Sh. (1984). Phys. Status Solidi A, 84, 79-86.

Pichaud, B., Burle-Durbec, N., Minari, F. \& Duseaux, M. (1985). J. Cryst. Growth, 71, 648-654.

TANNER, B. K. (1976). X-ray Diffraction Topography. Oxford: Pergamon Press.

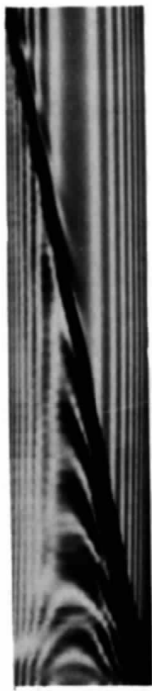

(a)

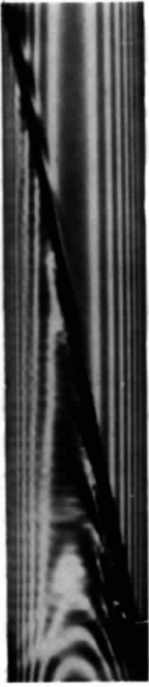

(b)

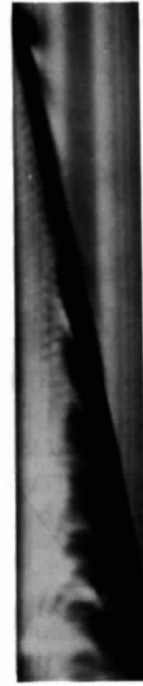

$(c)$
Fig. 3. Computed section topographs. (a) $\mathbf{b}=a / 3$ [111], $\mathbf{g}=\overline{4} 40$, entrance slit $=0.001 \mathrm{~mm},(b) \mathbf{b}=a / 2[110], \mathbf{g}=\overline{4} 40$, entrance slit $=$ $0.001 \mathrm{~mm},(c) \mathbf{b}=a / 3[111], \mathbf{g}=\overline{4} 40$, entrance slit $=0.017 \mathrm{~mm}$. 